\title{
Renal Hypertrophy
}

National Cancer Institute

\section{Source}

National Cancer Institute. Renal Hypertrophy. NCI Thesaurus. Code C122991.

Global enlargement of the renal parenchyma in one or both kidneys. 